\title{
HCV genotype 1a shows a better virological response to antiviral therapy than $\mathrm{HCV}$ genotype $1 \mathrm{~b}$
}

Adriano M Pellicelli ${ }^{1 *}$, Mario Romano ${ }^{2}$, Tommaso Stroffolini ${ }^{3}$, Ettore Mazzoni ${ }^{4}$, Fabrizio Mecenate ${ }^{5}$, Roberto Monarca ${ }^{6}$, Antonio Picardi $^{7},{ }^{2}$ Maria Elena Bonaventura ${ }^{8}$, Cristina Mastropietro $^{9}$, Pascal Vignally ${ }^{10}$, Arnaldo Andreoli ${ }^{1}$, Massimo Marignani ${ }^{11}$, Cecilia D’Ambrosio ${ }^{1}$, Lucia Miglioresi ${ }^{1}$, Lorenzo Nosotti ${ }^{12}$, Olga Mitidieri ${ }^{13}$, Umberto Vespasiani Gentilucci ${ }^{7}$, Claudio Puoti ${ }^{13}$, Giuseppe Barbaro ${ }^{14}$, Angelo Barlattani ${ }^{15}$, Caterina Furlan ${ }^{3}$ and Giorgio Barbarini ${ }^{16}$ and for the CLEO Group

\begin{abstract}
Background: The impact of viral subtype on the rate of sustained virological response (SVR) to antiviral therapy in patients chronically infected with hepatitis $C$ genotype 1 subtype $1 \mathrm{a}$ and $1 \mathrm{~b}$ has not been extensively investigated. The aim of this study is to determine whether the HCV genotype 1 subtypes $1 \mathrm{a}$ and $1 \mathrm{~b}$ respond differently to treatment with PEGylated interferon (PEG-IFN) plus ribavirin.

Methods: For 48 weeks, 388 "naïve"genotype 1 patients were treated weekly with PEG-IFN $a-2 a$ or PEG-INF a-2b combined with daily ribavirin (1000-1200 mg/day). The numbers of patients in whom HCV-RNA was undetectable were compared after 4 (rapid virological response, RVR), 12 (early virological response, EVR), and 48 (end treatment virological response, ETR) weeks of treatment as well as 24 weeks after the last treatment (sustained virological response, SVR).
\end{abstract}

Results: The rate of SVR was higher in subtype 1a patients than subtype $1 \mathrm{~b}$ patients ( $55 \%$ vs. $43 \% ; p<0.02$ ). Multiple logistic regression analysis showed that infection with genotype 1a (odds ratio(OR) : 1.8; 95\% confidence interval (Cl): 1.4 to 4.1), age < 50 years (OR:7.0; $95 \% \mathrm{Cl} 1.1$ to 21.2), alanine aminotransferase level (ALT) $<100 \mathrm{IU} / \mathrm{ml}$ (OR:2.1; 95\% Cl: 1.3 to3.5), HCV-RNA < $5.6 \log _{10} \mathrm{IU} / \mathrm{ml}$ (OR: 3.2; 95\% Cl: 2.7 to 6.9) and fibrosis score < S3 (OR: 3.8; 95\% Cl:3.2 to 7.4), were all independent predictors of SVR.

Conclusion: Dual antiviral therapy is more effective against HCV subtype 1a than against subtype $1 \mathrm{~b}$ and this difference is independent of other factors that may favour viral clearance.

Trial registration: ClinicalTrials.gov Identifier: NCT01342003

Keywords: Genotype 1a, HCV genotype 1 subtypes, Sustained virological response, Antiviral therapy, Pegylated interferon

\footnotetext{
* Correspondence: adriano.pellicelli@tiscali.it

${ }^{1}$ Liver Unit Azienda Ospedaliera San Camillo Forlanini, Circonvallazione Gianicolense, 87 00149, Rome, Italy

Full list of author information is available at the end of the article
} 


\section{Background}

Despite the promise of new antiviral drugs that can act directly on hepatitis $C$ viral replication such as protease and polymerase inhibitors, a 48 weeks course of PEGylated interferon (PEG-INF) combined with ribavirin remains the current standard treatment for genotype 1 chronic hepatitis $\mathrm{C}(\mathrm{CHC})[1,2]$. Extensive research has shown that patients infected with $\mathrm{HCV}$ genotype 1 have a lower rate of viral response than those infected with genotype 2 or 3 . In large randomized multinational trials, PEGylated interferon $\alpha$-2a plus ribavirin has produced an SVR of about $50 \%$ in the more difficult-to-treat subgroup of patients infected with HCV genotype $1[3,4]$. Furthermore, advanced fibrosis is a predictor of non response to antiviral treatment in patients with genotype 1 virus [5-7]. Very few studies have examined whether the subtype of genotype 1(1a or 1b) affects the rate of SVR [7-10].

We have performed an observational study on a large cohort of "naïve" HCV patients to evaluate the influence of HCV subtypes 1 on the response to treatment with PEG-INF plus ribavirin.

\section{Methods}

\section{Patients}

A total of 11 regional centres affiliated with the CLEO Group partecipate in the study between February 2007 and October 2010. Eligible subjects were naïve patients infected with $\mathrm{HCV}$ genotype 1 virus who met the internationally recognised criteria for treatment (elevation of aminotransferases and inflammation and/ or fibrosis at liver biopsy). The exclusion criteria included co-infection with human immunodeficiency virus (HIV) or hepatitis B virus (HBV), alcohol intake averaging greater than $20 \mathrm{~g}$ per day, active drug abuse, chronic systemic disease, psychiatric disorders, autoimmune disease, pregnancy or lactation. The following data were collected: age, gender, body mass index (BMI) and Ishak score of liver biopsy [11]. Of the 388 patients, 322 provided informed consent for liver biopsy.

All patients received Peg-IFN $\alpha$-2a at $180 \mu \mathrm{g} /$ week or PEG-INF $\alpha-2 b$ at $1.5 \mu \mathrm{g} / \mathrm{kg} /$ week combined with ribavirin at $1000 \mathrm{mg} /$ day if the body weight was $<75 \mathrm{Kg}$ or $1200 \mathrm{mg} /$ day if the body weight was $>75 \mathrm{~kg}$. The dose of PEG-INF and ribavirin were modified as necessary according to the standard criteria and protocol [12]. Patients with undetectable HCVRNA at week 4 were considered rapid virological responders (RVR) and were treated for full 48 weeks. Patients with a $<2 \log$ decline in HCVRNA at week 12 or who remained HCVRNA positive at week 24 were considered to be non-responders and did not continue with the treatment regimen. All patients who withdrew from the study were also defined as non-responders. The primary end point was sustained undetectable serum HCVRNA 24 weeks after the end of treatmen (SVR).

\section{HCVRNA quantification}

Quantitative determination of HCVRNA (TaqMan Roche Diagnostics). was performed before the treatment. The TaqMan value used to determine the response was $15 \mathrm{IU} /$ $\mathrm{ml}$. The TaqMan method is a standardised technique that was used in all the CLEO group centres beginning in December 2007. HCVRNA level was expressed as $\log _{10}$ $\mathrm{IU} / \mathrm{ml}$. HCVRNA was measured before the treatment, at weeks 4,12,24,48 of treatment and 24 weeks after the final treatment. HCV genotyping was performed using a hybridisation technique (INNOLiPA HCV Immunogenetics).

\section{Statistical analysis}

All analysis were performed on the basis of the intention to treat (ITT);i.e., the denominator included all subjects who received at least 1 dose of treatment.

Statistical analysis was performed using the Epiinfo software package. All Data were expressed as the median and range for discrete variables and as counts and percentages for qualitative variables. The differences between the groups were compared using non parametric tests (the Mann Whitney $U$ test for continuous variables and $x^{2}$ test for parametric variables). A $p$ value of $<0.05$ was considered to be significant.

The crude odds ratios (O.R s) for the association of SVR with different variables were evaluated by univariate analysis. The following variables were analyzed: sex, age (cut-off 50 years), ALT (cut-off $100 \mathrm{IU} / \mathrm{ml}$ ), gammaglutamyltranspeptidase (GGT), BMI (cut-off 24.9), HCVRNA (cut-off 400,000 IU/ml), HCV genotype 1 subtype ( $1 \mathrm{a}$ or $1 \mathrm{~b}$ ), liver biopsy grade and stage score, and type of PEGylated interferon received. The adjusted O.R. were calculated by multiple logistic regression analysis in order to identify independent predictors of SVR. Adjustment were made for all of the variables considered at univariate analyses.

\section{Ethics}

The study was approved by a central ethic committee (San Camillo Hospital Rome Italy).

\section{Results}

The study included 388 patients; of these 165 were infected with HCV genotype 1 subtype 1a (42.5\%) and 223 with subtype $1 \mathrm{~b}$ (57.5\%). On average, subtype 1a patients were younger and had lower baseline HCVRNA levels than subtype $1 \mathrm{~b}$ patients. All the baseline characteristics of the 388 patients are reported in Table 1. 
Table 1 Baseline Characteristics of study population according to HCV subtype

\begin{tabular}{|c|c|c|c|}
\hline & Genotype $1 \mathrm{a}(\mathrm{n}=165)$ & Genotype $1 b(n=223)$ & $P$ value \\
\hline $\operatorname{Sex}(M / F)$ & $120 / 45$ & $123 / 100$ & 0.001 \\
\hline Age $(y)$ & $45.0 \pm 10.6$ & $49.0 \pm 12.1$ & 0.0001 \\
\hline $\mathrm{BMI}\left(\mathrm{kg} / \mathrm{m}^{2}\right)$ & $24.1 \pm 3.2$ & $24.0 \pm 3.3$ & ns \\
\hline ALT (IU/ml) & $109.2 \pm 68.7$ & $101.4 \pm 61.2$ & ns \\
\hline GGT (IU/ml) & $65.1 \pm 39.1)$ & $67.3 \pm 54.5$ & ns \\
\hline $\mathrm{Hgb}(\mathrm{gr} / \mathrm{dL})$ & $15.2 \pm 1.3$ & $14.8 \pm 1.9$ & ns \\
\hline HCV-RNA ( $\left.\log _{10} \mathrm{IU} / \mathrm{ml}\right)$ & $5.72 \pm 0.7$ & $5.9 \pm 0.5$ & 0.006 \\
\hline \multicolumn{4}{|l|}{ HCV-RNA n (\%) } \\
\hline$\leq 5.60 \log _{10}$ & $52(32)$ & $44(20)$ & 0.01 \\
\hline$>5.60 \log _{10}$ & $113(68)$ & $179(80)$ & 0.01 \\
\hline \multicolumn{4}{|l|}{ Staging n (\%) } \\
\hline$\leq \mathrm{S} 3$ & $111(85)$ & $151(79)$ & ns \\
\hline$>\mathrm{S} 3$ & $19(15)$ & $41(21)$ & ns \\
\hline \multicolumn{4}{|l|}{ Source of Infection n (\%) } \\
\hline$-B T$ & $69(41)$ & $85(38)$ & ns \\
\hline$-D A$ & $78(47)$ & $92(41)$ & ns \\
\hline$-S$ & $8(5)$ & $15(7)$ & ns \\
\hline$-U N$ & $11(7)$ & $32(14)$ & 0.03 \\
\hline
\end{tabular}

Legend: M: male, F: female, y:years, BMI: body mass index, ALT: alanine aminotransferase value, GGT: gamma-glutamiltranspeptidasi, Hgb:Haemoglobin value, BT: blood trasfusione, DA:drug abuse, S: sexual, UN: unknown.

\section{Virological response}

At week 4 of treatment HCV-RNA was undetectable (RVR) in 77 genotype 1a patients (47\%) and in 83 genotype $1 \mathrm{~b}$ patients $(37 \%)(\mathrm{p}<0.07)$. At week 12 of treatment 91 genotype 1a patients $(55 \%)$ and 99 genotype $1 \mathrm{~b}$ patients $(44 \%)$ had undetectable HCV-RNA (early virological response; EVR) $(\mathrm{p}<0.04)$. At the end of treatment 108 genotype 1a patients (65\%) and 131 genotype $1 \mathrm{~b}$ patients $(58 \%)$ had undetectable HCV-RNA $(\mathrm{p}=\mathrm{n} . \mathrm{s})$. Seventeen (10\%) of the genotype 1a patients and 32
(14\%) of the genotype $1 \mathrm{~b}$ had detectable HCVRNA at week 12 but not at week 24 (slow responders) $(\mathrm{p}=\mathrm{ns}$ ). At the end of the treatment, there were $16(9 \%)$ relapsed patients in the genotype 1a group and $35(15 \%)$ in the genotype $1 \mathrm{~b}$ group $(\mathrm{p}=\mathrm{ns})$. Sustained virological response was attained in 91 genotype 1a patients (55\%) and 96 genotype $1 \mathrm{~b}$ patients $(43 \%)(\mathrm{p}<0.02)$. A total of 18 genotype $1 \mathrm{a}$ and 16 genotype $1 \mathrm{~b}$ patients discontinued all treatments at some time during the study owing due adverse events (Figure 1).

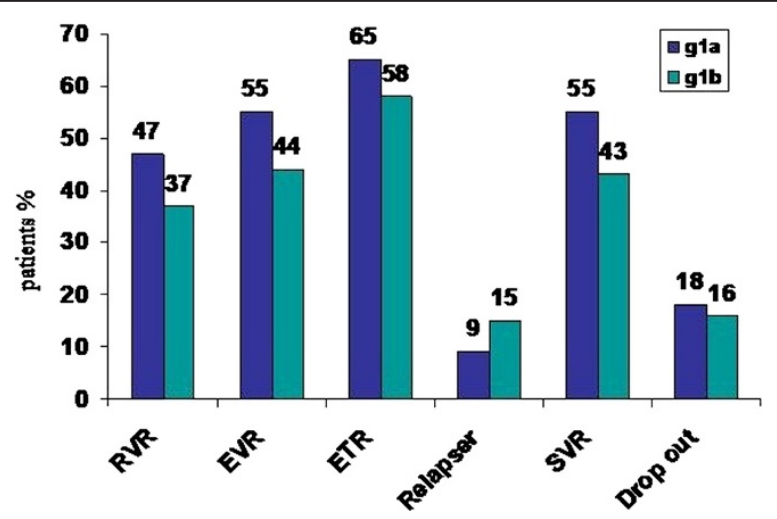

Figure 1 Rapid virological response (RVR), early virological response (EVR), end treatment virological response (ETR), sustained virological response (SVR) and drop out in genotype 1 subtypes $1 \mathrm{a}$ and $1 \mathrm{~b}$ patients. 
Table 2 Overall SVR according to different variables

\begin{tabular}{|c|c|c|c|}
\hline Variable & $\mathrm{N}^{\circ}$ of pts/Tot pts & SVR (\%) & $P$ value \\
\hline \multicolumn{4}{|l|}{ Sex } \\
\hline $\mathrm{F}$ & $68 / 145$ & 46 & ns \\
\hline M & $119 / 243$ & 49 & \\
\hline \multicolumn{4}{|l|}{ Age } \\
\hline$<50$ & $123 / 210$ & 58 & 0.00001 \\
\hline$>50$ & $64 / 178$ & 37 & \\
\hline \multicolumn{4}{|l|}{ BMI } \\
\hline$<25$ & $145 / 280$ & 51 & 0.05 \\
\hline$>25$ & $32 / 82$ & 39 & \\
\hline \multicolumn{4}{|l|}{ ALT } \\
\hline$<100$ & $139 / 261$ & 53 & 0.002 \\
\hline$>100$ & $51 / 127$ & 40 & \\
\hline \multicolumn{4}{|l|}{ HCV-RNA } \\
\hline$\leq 5.60 \log _{10}$ & $64 / 96$ & 66 & 0.00004 \\
\hline$>5.60 \log _{10}$ & $123 / 292$ & 42 & \\
\hline \multicolumn{4}{|l|}{ Genotype } \\
\hline $1 a$ & $91 / 165$ & 55 & 0.02 \\
\hline $1 b$ & $96 / 223$ & 43 & \\
\hline \multicolumn{4}{|l|}{ Staging* } \\
\hline$\leq \mathrm{S} 3$ & $142 / 262$ & 54 & 0.00008 \\
\hline$>\mathrm{S} 3$ & $15 / 60$ & 25 & \\
\hline \multicolumn{4}{|l|}{ Drug } \\
\hline PegINF a 2b & $100 / 195$ & 51 & ns \\
\hline PegINF a 2a & 87/193 & 45 & \\
\hline \multicolumn{4}{|l|}{ RVR } \\
\hline Yes & $129 / 160$ & 80 & 0.000001 \\
\hline No & $58 / 228$ & 25 & \\
\hline
\end{tabular}

Legend. SVR: sustained virological response, F: female, M:male, PegINF: pegylated interferon, BMI: body mass index, ALT: alanine aminotransferase value (IU/ml); RVR: rapid virological response.

*322 over 388 patients were submitted to liver biopsy and analyzed for this variable.

\section{Sustained virological response}

The overall rate of SVR was 48.2\%. Subtype 1a, age $<50$ years, ALT value $<100 \mathrm{IU} / \mathrm{ml}, \mathrm{HCV}-\mathrm{RNA}<400.000 \mathrm{IU} / \mathrm{ml}$ $\left(<5.60 \log _{10} \mathrm{IU} / \mathrm{ml}\right)$, and fibrosis score $\leq \mathrm{S} 3$ were all factors predisposing to SVR (Table 2). The rate of SVR in patients with fibrosis score S0-S3 was significantly higher for subtype 1a (62\%) than for subtype $1 \mathrm{~b}(48 \%)$ ( $\mathrm{p}<0.03)$; while no statistically significant difference in SVR was observed between the 2 subtypes ( $1 \mathrm{a}$ and $1 \mathrm{~b}$ ) in patients scoring S4-S6 (31.5\% vs. 28\%; p = n.s.).(Data not shown).

Table 3 shows the crude and adjusted Odds Ratios (ORs) for the associations of different variables with SVR. After adjustment for the influence of the confounding variables by logistic regression analysis, age < 50 (OR:7.0; 95\% CI: 1.1 to 21.1 ), genotype 1a (OR: 1.8 ; 95\% CI: 1.4 to 4.1), HCV-RNA < $5.6 \log _{10} \mathrm{IU} / \mathrm{ml}$ (OR: 3.2; 95\% CI: 2.7 to
Table 3 Factors associated with the likelihood of SVR. Crude and adjusted Odds Ratios (O.R.) derived by multiple logistic regression analysis

\begin{tabular}{|c|c|c|c|}
\hline & Crude O.R. (95\% Cl) & Adjusted O.R. & (C.I. 95\%) \\
\hline $\begin{array}{l}\text { HCV-RNA } \leq 5.6 \log _{10} \\
\mathrm{IU} / \mathrm{ml}\end{array}$ & $2.9(1.8-5.1)$ & 3.2 & $(2.7-6.9)$ \\
\hline$\leq \mathrm{S} 3^{*}$ & $3.8(2.0-7.3)$ & 3.8 & $(3.2-7.4)$ \\
\hline Subtype 1a & $1.9(1.2-2.9)$ & 1.8 & $(1.4-4.1)$ \\
\hline Age & $7.4(0.9-40.0)$ & 7.0 & $(1.1-21.2)$ \\
\hline \multicolumn{4}{|l|}{$<50$} \\
\hline \multicolumn{4}{|l|}{$>50$} \\
\hline BMI & $1.7(1.0-2.8)$ & 1.4 & $(0.8-2.5)$ \\
\hline \multicolumn{4}{|l|}{$<25$} \\
\hline \multicolumn{4}{|l|}{$>25$} \\
\hline ALT & $1.9(1.2-3.0)$ & 2.1 & $(1.3-3.5)$ \\
\hline \multicolumn{4}{|l|}{$<100$} \\
\hline \multicolumn{4}{|l|}{$>100$} \\
\hline Sex & $1.1(0.7-1.7)$ & 1.3 & $(0.8-2.2)$ \\
\hline RVR & $21.0(11.5-38.3)$ & 3.2 & $(1.3-7.7)$ \\
\hline
\end{tabular}

6.9), a fibrosis score $\leq \mathrm{S} 3$ (OR: 3.8; $95 \% \mathrm{CI}: 3.2$ to $7.4 ;$ ), and ALT value $<100 \mathrm{IU} / \mathrm{ml}$ (OR:2.1 95\% CI: 1.3 to 3.5) were all independent predictors of SVR while sex, and BMI were not associated with SVR.

Cross-tabulation of RVR vs.SVR showed that the positive predictive value (PPV) of RVR for the achievement of SVR was $82.0 \%$ for subtype 1 a and $77.4 \%$ for subtype $1 \mathrm{~b}$ (data not shown).

Table 4 Total discontinuation, dose modification and adverse events related to antiviral treatment

\begin{tabular}{lcc}
\hline & Subtype 1a $\mathbf{~ n = 1 6 5}$ & Subtype 1 b $\mathbf{~}=\mathbf{2 2 3}$ \\
\hline Total discontinuation n (\%) & $18(11)$ & $16(7.1)$ \\
-depression & $7(4.2)$ & $3(1.3)$ \\
-fatigue & $10(6)$ & $9(4)$ \\
-hyperthiroidism & 0 & $1(0.4)$ \\
-anemia & $1(0.6)$ & $3(1.3)$ \\
Adverse events n (\%) & $7(4.2)$ & $12(5.3)$ \\
-depression & $1(0.6)$ & $3(1.3)$ \\
-hypothiroidism & $1(0.6)$ & 0 \\
-anemia & $5(3.0)$ & $7(3.1)$ \\
-neutropenia & 0 & $2(0.9)$ \\
Dose modification $n(\%)$ & $16(9.6)$ & $24(10.7)$ \\
Peginterferon & $9(5.4)$ & $11(5)$ \\
Ribavirin & $7(4.2)$ & $13(5.8)$ \\
\hline
\end{tabular}

n:number. 


\section{Safety profile}

Eighteen subtype 1a (11\%) and 16 subtype 1b (7\%) patients stopped antiviral treatment due to adverse effects. Six patients stopped during the first month of treatment and the remaining patients during the following months. The percentage of patients in both groups whose treatment dose were decreased due to adverse events were comparable: $9.6 \%$ (16 patients) for subtype 1a and $10.7 \%$ (24 patients) for subtype $1 \mathrm{~b}$. Anaemia was the most frequent cause of dose reduction. Total discontinuation, dose modifications and adverse events related to treatment are showed in Table 4.

\section{Discussion}

We have conducted a large observational study to assess the influence of viral subtype within HCV genotype 1 on the virological response to antiviral treatment in naïve HCV patients. Logistic regression analysis showed that HCV subtype 1a, mild liver fibrosis scored as less than S3 (Ishak score), HCV-RNA level less than $5.6 \log _{10}$ $\mathrm{IU} / \mathrm{ml}$, age less than 50 years, and ALT level less than $100 \mathrm{IU} / \mathrm{ml}$ were all independent predictors of SVR.

Many efforts have been made to identify predictors of SVR to antiviral treatment in the difficult-to- treat chronic hepatitis $\mathrm{C}$ genotype 1 patients. Liver histology and viral HCV-RNA levels seem to be particularly important predictor of response in these patients. A recent study by Cheng et al. showed that naive genotype- 1 patients with advanced fibrosis were less likely to achieve SVR than those without advanced fibrosis [5]. Bruno et al. demonstrated that age and liver fibrosis predicted the response rate to PEG-INF and ribavirin combination therapy [6]. Few studies have investigated the impact of viral subtype on SVR genotype 1 patients. A study by Legrand-Abravanel et al. showed by multivariate analysis that genotype 1 subtype 1a was associated with a lower response to HCV therapy than subtype $1 \mathrm{~b}$ [8]. However, this was an observational study with some potential confunding factors: more than $23 \%$ of the patients were concomitantly infected with HIV or HBV; and nearly $35 \%$ were interferon experienced patients. Similarly, Nicot et al. found that genotype $1 \mathrm{~b}$ and HCVRNA $<15 \mathrm{IU} / \mathrm{ml}$ were the only independent predictors of SVR in genotype 1 patients. However the population of patients analysed in this study was not homogeneous: $23 \%$ of all patients were coinfected with HIV and $42 \%$ had not responded to previous interferon treatment [9]. Zein et al. found no difference in SVR rates between subtype 1a and $1 \mathrm{~b}$ patients treated with standard interferon [13]. The PROBE study, which included more than $6000 \mathrm{HCV}$ infected patients, showed that SVR was marginally associated with subtype 1a ( OR 1.41; 95\% CI 1.0-2.03) [7]. A recent observational study with a retrospective and prospective phase conducted in Italy (AIFA study), which included naïve, relapser and no responder patients, showed that genotype 1a naive patients experienced a rate of SVR around 6\% higher than that observed for genotype $1 \mathrm{~b}$ naïve patients and comparable to that observed in genotype 4 (retrospective phase-SVR G1a versus G1b 37.1 vs $31.6 \% \mathrm{p}<0.001$ and prospective phase-SVR 31.0 vs $26.5 \% \mathrm{p}<0.001$ ) [10]. A higher rate of adverse events and in particular of anemia reported in AIFA study, could have influenced the different rate of SVR observed respect to our study. We hypothesize that, in particular, an high rate of anemia could have been responsible for ribavirin or peginterferon dose modification in the AIFA study (data not reported).

Genotype 1 subtypes $1 \mathrm{a}$ and $1 \mathrm{~b}$ are the most common HCV genotypes in the United State. These subtypes are also predominant in Europe and subtype $1 \mathrm{~b}$ is responsible for up to $73 \%$ of $\mathrm{HCV}$ infection in Japan. Zein et al. found that patients with HCV subtype $1 \mathrm{~b}$ were older on average than those infected with other genotypes and that subtype $1 \mathrm{~b}$ may have been present in some countries before the other genotypes. All patients who acquired $\mathrm{HCV}$ before 1955 were infected with subtype 1b. Subtype 1a was introduced in the late 1950s and then, it became the most prevalent genotype [13]. According to this model HCV subtype $1 \mathrm{~b}$ is associated with more severe liver disease not because it is a more aggressive form of HCV but because it reflect a longer duration of infection [14]. In our study more genotype $1 \mathrm{~b}$ than genotype 1a patients relapsed after treatment although the difference was not statistically significance. This difference could have been due to the higher percentage of slow responding patients in genotype $1 \mathrm{~b}$ group than in genotype 1a group. Some studies have demonstrated a significant association between slow response and relapse in patients with an EVR[15,16]. Although genotype 1a present a lower age and lower baseline HCVRNA level respect to genotype $1 \mathrm{~b}$ patients, the logistic regression analysis and in particular Adjusted odds ratio shows the independent influence of genotype 1a on SVR without the disturbing influence of other variables. For the above- mentioned reasons subtype $1 \mathrm{~b}$ patients may respond less favourably than subtype 1a patients to PEG-INF plus ribavirin.

While we observed in dual antiviral therapy a better SVR of genotype 1a respect to genotype $1 \mathrm{~b}$ patients, genotype 1a presents higher virologic failure respect to genotype $1 \mathrm{~b}$ in patients treated with triple antiviral combination therapy including protease inhibitors Boceprevir or Telaprevir. Overall, the barrier to resistance is lower in genotype 1a than in genotype $1 \mathrm{~b}$ strains, resulting in higher breakthrough rates in the former [17].

In our study we found similar SVR in patients treated with pegylated interferon alfa-2a and alfa 2 -b, this is in agreement with Ideal and AIFA study $[10,18]$ but it is in 
contrast with two italian randomized controlled studies that demonstrated higher SVR in genotype 1 patients treated with pegylated interferon alfa-2a $[19,20]$. At present the superiority of one regimen over the other in terms of treatment efficacy remains unknown. The performance of the two drugs has not been explored in patients stratified by treatment modifiers such as fibrosis stage, basal viral load, insulin resistance, age and it is unlikely that future effort will extend current knowledge as we enter in the era of protease and polymerase inhibitors [21].

The interleukin-28B (IL28B) polymorphism has been reported to influence viral kinetics and SVR in genotype 1 patients [22]. We did not determine this parameter in the present study; its significance was not known at the time that the study was conducted. Therefore, we cannot exclude the possibility that our subtype 1a patients may have had a more favourable IL28B polymorphism profile than did the subtype 1b patients. IL28B polymorphism could be an additional parameter explaining the uniquely higher SVR rate for subtype $1 \mathrm{a}$ versus $1 \mathrm{~b}$ observed in the Italian population.

Finally, we would like to emphasise that this study was conducted in "real- world- patients", thus providing a representative picture of $\mathrm{HCV}$ treatment.

\section{Conclusion}

While in triple antiviral combination therapy including protease inhibitors Boceprevir or Telaprevir genotype 1a presents higher virologic failure respect to genotype $1 \mathrm{~b}$ patients, we observed in dual antiviral therapy a better SVR of genotype 1a respect to genotype $1 \mathrm{~b}$ patients that is independent of other factors that may favour viral clearance.

\section{Competing interests}

All the authors declares the they not have received reimbursements, fees, funding, or salary from an organization that may in any way gain or lose financially from the publication of this manuscript, either now or in the future. All the authors declares that they do not hold any stocks or shares in an organization that may in any way gain or lose financially from the publication of this manuscript, either now or in the future. All the authors declare that they do not hold or apply any patents relating to the content of the manuscript. All the authors declare that they have not received reimbursements, fees, funding, or salary from an organization that holds or has applied for patents relating to the content of the manuscript. All the Authors declare that they not have any other financial competing interests.

\section{Authors' contributions}

AMP Concept-Design-Manuscript editing-Manuscript review-Manuscript preparation, Data acquisition MR Concept-Design-Literature search manuscript review, manuscript preparation, TS Statistical analysis, manuscript editing, manuscript review. LN Data acquisition, literature search. FM Data acquisition, manuscript review. CP Data acquisition, manuscript preparation, analysis of laboratory data. GB Statistical analysis, Manuscript review. RM Data acquisition and manuscript review. EM Manuscript editing, Data acquisition. AP Data acquisition. MEB Manuscript review, data acquisition. CM Data acquisition. PV statistical analysis, data acquisition, manuscript editing. AA Manuscript editing, literature search. MM Literature search, data acquisition. CD Manuscript preparation, Data acquisition, Concept. LM Manuscript review, Data acquisition. OM Laboratory analysis, Data acquisition. UVG data acquisition. Manuscript preparation. CF Manuscript review and preparation, critical review of the mauscript AB Manuscript preparation, Data acquisition. GB Data acquisition, Manuscript preparation-Literature search, Manuscript review. All the authors read and approved the final manuscript

\section{Author details}

${ }^{1}$ Liver Unit Azienda Ospedaliera San Camillo Forlanini, Circonvallazione Gianicolense, 87 00149, Rome, Italy. ${ }^{2}$ Liver Unit Ospedale Sandro Pertini, Via dei Monti Tiburtini 385, 00157, Rome, Italy. ${ }^{3}$ Department of Infectious and Tropical Disease Policlinico Umberto I, Viale del Policlinico 155, 00161, Rome, Italy. ${ }^{4}$ Liver Unit Policlinico Casilino, Via Casilina, 1049-00169, Rome, Italy. ${ }^{5}$ Liver Unit Ospedale Villa Betania, Via Niccolò Piccolomini 27, 00165, Rome, Italy. ${ }^{6}$ Infectious Disease Ospedale di Belcolle strada Sammartinese, 01100 , Viterbo, Italy. ${ }^{7}$ Liver Unit Campus Biomedico University, Via Álvaro del Portillo, 21 00128, Rome, Italy. ${ }^{8}$ Infectious Disease Ospedale San Camillo de Lellis, Via John Fitzgerald Kennedy, 02100, Rieti, Italy. ${ }^{9}$ Department of Infectious Disease Policlinico Umberto I, Viale del Policlinico 155, 00161, Rome, Italy. ${ }^{10}$ National Institute of Health, Viale Regina Elena 299, 00161, Rome, Italy.

${ }^{11}$ Department of Digestive and Liver Disease, Azienda Ospedaliera Sant'Andrea, Via Grottarossa, 1035/1039, Rome, Italy. ${ }^{12}$ Medicine of Migration National Institute for Migrant Health and Poverty, Via di S. Gallicano 25/a, 00153, Rome, Italy. ${ }^{13}$ Department of Internal Medicine and liver unit Ospedale Generale di Marino, Viale XXIV Maggio, 00047, Marino Rome, Italy. ${ }^{14}$ Department of Medical Pathophysiology, University of Rome La Sapienza, Viale del Policlinico 155, 00161, Rome, Italy. ${ }^{15}$ Liver Unit ASL RM/A, Rome, Italy. ${ }^{16}$ Infectious and Parasitic Diseases, Policlinico San Matteo P.zzale Golgi,2, 27100, Pavia, Italy.

Received: 18 June 2012 Accepted: 13 November 2012

Published: 16 November 2012

\section{References}

1. McHutchison JG, Everson GT, Gordon SC, et al: PROVE1 Study Team. Telaprevir with peginterferon and ribavirin for chronic HCV genotype 1 infection. N Engl J Med 2009, 360:1827-1838.

2. Kwo PY, Lawitz EJ, McCone J, et al: SPRINT-1 investigators. Efficacy of boceprevir, an NS3 protease inhibitor, in combination with peginterferon alfa- $2 \mathrm{~b}$ and ribavirin in treatment-naive patients with genotype 1hepatitis C infection (SPRINT-1): an open-label, randomised, multicentre phase 2 trial. Lancet 2010, 376:705-716.

3. Fried MW, Shiffman ML, Reddy K, et al: Peginterferon alfa-2a plus ribavirin for chronic hepatitis C virus infection. N Engl J Med 2002, 347:975-982.

4. Hadziyannis SJ, Sette H Jr, Morgan TR, et al: PEGASYS International Study Group. Peginterferon-alpha2a and ribavirin combination therapy in chronic hepatitis C: a randomized study of treatment duration and ribavirin dose. Ann Intern Med 2004, 140:346-355.

5. Cheng WS, Roberts SK, McCaughan G: Low virological response and high relapse rates in hepatitis $C$ genotype 1 patients with advanced fibrosis despite adequate therapeutic dosing. J Hepatol 2010, 53:616-623.

6. Bruno $S$, Cammà $C$, Di Marco V, et al: Peginterferon alfa-2b plus ribavirin for naïve patients with genotype 1 chronic hepatitis C: a randomized controlled trial. Hepatol 2004, 41:474-481.

7. Rizzetto $M$, Colombo $M$, Ascione $A$, et al: Effectiveness of hepatitis $C$ virus treatment in real life practice: a prospective observational multicenter study in Italy (PROBE). J Hepatol 2008, 2(48):S311.

8. Legrand-Abravanel F, Colson P, Leguillou-Guillemette L, et al: Influence of the HCV subtype on the virological response to pegylated interferon and ribavirin therapy. J MedVirol 2009, 81:2029-2035.

9. Nicot F, Alric L, Barange $K$, et al: Influence of genotype 1 subtypes on the virus response to Peg interferon alpha-2a plus ribavirin therapy. J Med Virol 2011, 83:437-444

10. Rosina F, Tosti ME, Borghesio E, et al: PEG-IFN for chronic hepatitis C in clinical practice: the prospective phase of the AIFA study. Dig Liv Dis 2012, 44S:s12.

11. Knodell RG, Ishak KG, Black WC, et al: Formulation and application of a numerical scoring system for assessing histological activity in asymptomatic chronic active hepatitis. Hepatology 1981, 1:431-435.

12. Dienstag $\lrcorner$, McHutchinson J: American Gastroenterological association technical review on the management of hepatitis C. Gastroenterology 2006, 130:231-264. 
13. Zein NN, Rakela EL, Krawitt KR, Reddy KR, Tominaga T, Persing DH: Hepatitis C virus genotypes in United States: epidemiology, pathogenicity, and response to interferon therapy. Ann Intern Med 1996, 125:634-639.

14. Zein NN: Clinical significance of hepatitis $\mathbf{C}$ virus genotypes. ClinMicrobiol Rev 2000, 13:223-235.

15. Nevens E, Van Vlierberghe H, D'Heygere E, et al: BERNAR-1 Study Group. A randomized open label, multicenter studyevaluating the efficacy of peginterferon alfa $2 \mathrm{a}$, in combination with ribavirin, in naïve and relapsed chronic hepatitis C patient. Acta Gastroenterol Belg 2010, 73:223-228

16. Yu JW, Wang GQ, Sun $L$, Li XG, Li SC: Predictive value of rapid virological response and early virological response on sustained virological response in $\mathrm{HCV}$ patients treated with pegylated interferon alpha-2a and ribavirin. J GastroenterolHepatol 2007, 22:832-836.

17. Sarrazin C, Zeuzem S: Resistance to direct antiviral agents in patients with hepatitis C virus infection. Gastroenterology 2010, 138:447-462.

18. McHutchison JG, Lawitz EJ, Shiffman ML, et al: Peginterferon alfa-2b or alfa-2a with ribavirin for treatment of hepatitis C infection. N Engl J Med 2009, 361:580-593.

19. Ascione A, De Luca M, Tartaglione MT, et al: Peginterferon alfa-2a plus ribavirin is nore effective than peginterferon alfa- $2 b$ plus ribavirin for treating chronic hepatitis C virus infection. Gastroenterology 2010, 138:116-122.

20. Rumi MG, Aghemo A, Prati GM, et al: Randomized study of peginterferon alfa2a plus ribavirin vs peginterferon alfa $2 \mathrm{~b}$ plus ribavirin in chronic hepatitis C. Gastroenterology 2010, 138:108-115.

21. Rumi MG, Aghemo A, Prati GM: Comparative trials of peginterferon alfa2a and peginterferon alfa-2b for chronic hepatitis C. J Viral Hepatol 2012, 19:37-41.

22. Thompson AJ, Muir AJ, Sulkowski MS, et al: Interleukin-28B polymorphism improves viral kinetics and is the strongestpretreatment predictor of sustained virologic response in genotype 1 hepatitis C virus. Gastroenterology 2010, 2010(139):120-129.

doi:10.1186/1471-230X-12-162

Cite this article as: Pellicelli et al:: HCV genotype 1a shows a better virological response to antiviral therapy than $\mathrm{HCV}$ genotype $1 \mathrm{~b}$. BMC Gastroenterology 2012 12:162.

\section{Submit your next manuscript to BioMed Central and take full advantage of:}

- Convenient online submission

- Thorough peer review

- No space constraints or color figure charges

- Immediate publication on acceptance

- Inclusion in PubMed, CAS, Scopus and Google Scholar

- Research which is freely available for redistribution 